\title{
¿Distinción social o sociabilidad pura? El impulso civilizador en los salones aristocráticos y burgueses, según Elias y Simmel*
}

\author{
Alejandro Néstor García Martínez \\ Universidad de Navarra \\ angarcia@unav.es
}

\section{Resumen}

Las reuniones sociales elitistas y jerárquicas, en las que se difundían conductas protocolarias y se promovía un característico control afectivo, han sido centrales en el análisis del proceso de civilización en autores como Norbert Elias. No obstante, la investigación historiográfica y observaciones sociológicas como las de Simmel resaltan la existencia de salones sociales alternativos, donde el rango y la jerarquía quedaban en suspenso a favor de fines puramente eudemonísticos. Este artículo presenta las objeciones que los análisis de Elias han recibido ante estas evidencias. Se concluye que no afectan realmente a la centralidad de sus argumentos, aunque amplían fecundamente su perspectiva y sirven como complemento heurístico para la comprensión de los procesos civilizadores.

Palabras clave: salones sociales; proceso de civilización; sociabilidad.

Abstract. Social Distinction or Pure Sociability? The Civilizing Impulse to Aristocratic and Bourgeois Solons According to Elias and Simmel

Elitist and hierarchical social gatherings, wherein rules of civility were disseminated and specific affective control encouraged, have been central to the analyses of the process of civilization carried out by scholars such as Norbert Elias. However, historiographical research and sociological observation by other thinkers, including Simmel, discloses the existence of alternative social gatherings in which purely eudemonistic goals override the significance attributed to rank or hierarchy. This article presents the objections to Elias's approach arising from such research. The conclusion drawn here is that although the objections may broaden his perspective and contribute as a heuristic complement to a greater understanding of the processes of civilization, criticism of this kind does not have a significant bearing on Elias's central line of argument.

Key words: social gatherings; civilizing process; sociability.

* Este trabajo es resultado del proyecto de investigación «Filosofía moral y ciencias sociales» financiado por el Ministerio de Ciencia e Innovación (FFI 2009-09265). 


\begin{aligned} & \multicolumn{2}{c}{ Sumario } \\ & Introducción La sociabilidad pura en los salones \\ & Distinción social, sociedad cortesana e sociales \\ & impulso civilizador Conclusiones \\ & Revisión y ampliación de la tesis eliasiana Referencias bibliográficas \end{aligned}

\section{Introducción}

En su estudio sobre los procesos de civilización, Norbert Elias recurre a los salones aristocráticos para ilustrar una estructura social específica en la que comparece un «impulso civilizador». En particular, toma las reuniones sociales de la alta sociedad francesa como ejemplo de un entramado de relaciones - figuración - en donde se favorece la autocontención afectiva que caracteriza a los procesos civilizadores. Puede rastrearse todo su análisis sobre estos salones de la aristocracia francesa tanto en su magna obra El proceso de la civilización como en La sociedad cortesana. La idea que subyace a este respecto en ambos textos es que en los salones de la alta sociedad la función de distinción social y la jerarquía propiciaban un refinamiento de la conducta en la dirección del distanciamiento y la autocoacción, es decir, de la civilización como transformación del comportamiento humano.

Sin embargo, la revisión historiográfica y sociológica que se ha hecho de las tesis de Elias ha puesto de relieve la existencia de salones alternativos de alta sociedad y unas evidencias de las prácticas dentro de ellos que ponen en cuestión su formulación originaria. La constatación de esas otras formas de interacción social, en donde la jerarquía y los rangos quedaban en suspenso a favor de una finalidad puramente eudemonística, parece oponerse a los análisis eliasianos. En este artículo, se sostiene que tales objeciones, aunque son relevantes y sirven para ampliar la perspectiva del sociólogo de Breslau, no afectan de manera directa a la centralidad de sus argumentos, sino que proponen una alternativa que sirve como complemento heurístico para la comprensión de los procesos de civilización.

Para alcanzar esta conclusión, el artículo se divide en cuatro partes. En la primera, se esbozará la originaria propuesta de Norbert Elias en torno a la sociedad cortesana y los salones aristocráticos como nicho de un específico impulso civilizador en Occidente. La segunda parte presentará las objeciones básicas hechas a su modelo. Para ilustrar esas objeciones con un caudal sociológico de reflexión, en la tercera parte se completarán esas críticas con el análisis de Simmel sobre la lógica imperante en los salones sociales a los que él mismo acudió, y que, en su opinión, resultan ejemplares de lo que denomina sociabilidad pura. Finalmente, se propondrán algunas conclusiones que matizan las fuertes objeciones vertidas sobre la propuesta eliasiana. 


\section{Distinción social, sociedad cortesana e impulso civilizador}

La tesis de Elias sobre el proceso de civilización en Occidente consiste en vincular sinérgicamente los cambios acontecidos en las estructuras sociales con las transformaciones en las estructuras afectivas de las personas. La progresiva racionalización, contención y dominio de los impulsos, o, en suma, la creciente disciplinarización del yo que caracteriza al individuo civilizado, corre en paralelo a cambios sociales, tales como el monopolio de la violencia, el monopolio fiscal, la diferenciación social o las progresivas cadenas de interdependencia. Esta afinidad o conexión de sentido entre transformaciones sociales y afectivas es la que, en opinión de Elias, da cuenta de lo que puede comprenderse por el proceso de civilización.

En este contexto interpretativo, existen algunos momentos históricos y algunas estructuras sociales específicas que ejercen un nítido «impulso civilizador». Tal es el caso paradigmático de la sociedad cortesana. En este entramado social se muestra esa correspondencia entre una estructura específica de relaciones sociales y una configuración determinada de la afectividad humana. Y la propia lógica de esas estructuras particulares empuja o favorece el fortalecimiento de las transformaciones socioafectivas con las que Elias caracteriza los procesos de civilización. De acuerdo con sus estudios, las peculiaridades de la sociedad cortesana que fundamentan ese «impulso civilizador» en el sentido indicado precisan aclarar sus dos supuestos básicos:

Por un lado, los valores o las cuestiones axiológicas, que, encarnadas por los actores sociales de este entramado social, definen las aspiraciones, las estrategias y las acciones de los cortesanos.

Por otro lado, la específica situación relacional en la que queda la nobleza terrateniente en relación con la llamada «nobleza de toga», la burguesía en ascenso, y la posición real ocupada por el monarca con sus características distintivas.

Del desarrollo de estas dos líneas de fuerza se desprende la peculiar estructura socioafectiva que ejerce ese impulso en la dirección de la civilización, es decir, en la dirección de una creciente autocontención emocional y racionalización de las conductas, junto a una progresiva diferenciación y complejidad de las relaciones sociales.

\section{El honor como fundamento del ethos cortesano}

El primero de los aspectos cruciales para comprender cabalmente a la sociedad cortesana y el impulso civilizador que ejerce afecta a cuestiones axiomáticas básicas y compartidas por los individuos de este entramado. Dicho de otro modo, es preciso considerar los valores y los principios que definen el universo de lo deseable, lo digno de ser perseguido, pues prescriben las conductas adecuadas a tales fines irrenunciables. Las diferencias axiomáticas compartidas por los miembros de la sociedad cortesana son bien distintas de las propias de la sociedad burguesa: de ahí el impacto o la sacudida que pueden provocar 
determinadas conductas cortesanas si no se previene con anterioridad sobre esa diversidad de valores. Por ejemplo, el dispendio, el lujo superfluo, o incluso la preferencia de muchos nobles por arruinarse antes que prescindir de un consumo ostentoso - a menudo por encima de sus posibilidades materialessólo pueden comprenderse desde esos fundamentos axiológicos distintivos. Como afirma Weber:

El «lujo», en el sentido del rechazo de la orientación racional del uso, no es, para el estrato de los señores feudales, «superfluo», sino uno de los medios de su autoafirmación social. (Weber, 1922: 750; cfr. Elias, 1993b: 56)

Podemos usar el concepto de ethos cortesano para referirnos a tales valores irrenunciables que guían la conducta de los miembros de esta sociedad. A su vez, el término de honor sirve como concepto particular que manifiesta tal contenido axiomático. Así, para la nobleza cortesana, la vida honorable y el honor se caracterizan, principalmente, por la consideración profunda de la valía de su propia existencia social como grupo distanciado del resto de la población. Lo que su propia identidad significa para ellos no puede desvincularse de su pertenencia a un grupo social particular y distintivo, un grupo social dominante y privilegiado:

El deseo de sobresalir, de diferenciarse de los que no pertenecen a la misma clase, de distinguirse socialmente, encuentra su expresión lingüística en conceptos como «valeur», «considération», «se distinguer» y otros muchos, cuyo uso es evidentemente tanto un santo y seña de la pertenencia como una prueba de la vinculación a idénticos ideales sociales. (Elias, 1993b: 89-90)

Para los miembros de la sociedad cortesana, lo que otorga sentido a la propia existencia social y, en consecuencia, ejerce también como pauta normativa para la acción individual es la distancia respecto a todos los demás, es decir, su prestigio u honor. En palabras del propio Elias, «este destacarse y este pertenecer a la buena sociedad forman parte de los fundamentos constitutivos de la identidad personal, así como de la existencia social» (Elias, 1993b: 135). De acuerdo con esto, para la nobleza cortesana perder el honor, es decir, dejar de pertenecer a ese selecto grupo social, suponía «un peligro global para aquello que, en su sentimiento, daba sentido y valor a su vida» (Elias, 1993b: 105).

El honor como fundamento del ethos cortesano tiene una consecuencia directa: para preservarlo, los cortesanos deben comportarse externamente de acuerdo con las normas vigentes, pues la propia posición social es un reconocimiento otorgado por los demás, y como tal puede ser revocado. De este modo, el honor que da sentido y actúa como pauta normativa y teleológica de la sociedad cortesana no hace principalmente referencia a la propia posición social, sino más específicamente al reconocimiento - manifiesto o tácitopor parte de los demás miembros del grupo a la posición social ocupada. Por esta razón, para la preservación del honor y la pertenencia al grupo selecto no 
es suficiente con tener derecho de sangre para acceder a él, sino que resulta requisito ineludible la aceptación por parte de los demás de esa posición dentro del grupo social.

En suma, la condición para preservar el honor y la pertenencia al grupo diferenciado escomportarse de acuerdo con las normas sociales establecidas. Tales normas, como se puede anticipar, están en parte orientadas a la distinción del propio grupo con respecto a los demás estratos sociales. De aquí la característica tan propia de este tipo social conceptualizada como el «consumo de estatus» $\mathrm{o}$, en los términos que emplea Veblen en su análisis de la clase ociosa, de "consumo conspicuo" (Veblen, 1991). Y a la inversa, quien se comporta fuera de las pautas normativas establecidas para la posición social ocupadas corre el riesgo de perder esa posición y, con ella, el honor. En palabras de Elias:

[...] la manera esencial de realizar un rango es documentarlo mediante una conducta adecuada a ese rango, según el uso social. La coacción para que se represente el rango es implacable. Si se carece del dinero para ello, entonces el rango y, por tanto, la existencia social de su poseedor, gozan de una muy precaria realidad. Un duque que no vive como debe vivir un duque y que tampoco puede ya, en consecuencia, cumplir ordenadamente con las obligaciones sociales de ese rango, ya casi no es duque. (Elias, 1993b: 88)

\section{Figuración cortesana y circulación de modelos}

Teniendo en cuenta este universo axiomático y la idea de honor que sustenta la praxis de los miembros de la sociedad cortesana, puede explicarse la específica estructura de relaciones sociales en las que culmina. El proceso, expuesto por Elias en diversos lugares (cfr., especialmente, Elias, 1993b: 199-202, 220-225, 248-249), puede resumirse del siguiente modo: por contingencias históricas, las luchas entre grandes nobles y casas resulta en una ventaja competitiva de unos pocos y, en especial, del primus inter pares que representa la figura de Enrique IV. El proceso de pacificación de territorios cada vez más amplios supone un progresivo monopolio de la violencia junto a un creciente monopolio fiscal y recaudador, especialmente a cargo de ese noble prevalente y cada vez más distanciado del resto. A esta hegemonía de una casa y de un rey en particular contribuirán también otras contingencias históricas de índole más económica, como es la afluencia de metales provenientes de lejanos lugares que traerán consigo una devaluación de las rentas propiedad de los nobles terratenientes. Esta devaluación no afectará al rey, pues sus ingresos provenían principalmente de la recaudación y la venta de cargos. Así, conforme la nobleza se va arruinando, el rey es capaz de comprar mercenarios, proseguir con el proceso de pacificación y, con él, garantizar la recaudación tributaria, ampliando progresivamente su poder político y económico. Es lo que Elias resume con el concepto quizá poco apropiado (pues sugiere una necesidad histórica en este proceso que el propio autor no suscribe) de «mecanismo real» (Elias, 1993b: 400 y s.). 
La nobleza de espada, la propietaria de tierras y que vive de ellas, cada vez más necesita del favor real para poder compensar esa devaluación y proseguir con el estilo de vida y el gasto ostentoso que permite su reconocimiento como miembro del grupo diferenciado, es decir, que le permite mantener su honor. Algunos decidieron dejar de buscar el favor real a costa de perder su condición de pleno derecho del grupo selecto; pero, en general, todo este entramado condujo a la formación de la Corte como comunidad cercana al Rey, que le rinde pleitesía y va en busca continua de su favor para mantener su estatus social.

Es aquí, en estos salones aristocráticos y cortesanos, donde Elias sitúa un específico impulso en la dirección de la civilización: esta figuración refuerza la atención minuciosa a la propia conducta, el ocultamiento de las emociones y afectos, la búsqueda mediada, sutil y no impulsiva de oportunidades de poder. La atención a la conducta propia y ajena es exquisita, pues en las normas de etiqueta y ceremonial y en detalles menores y aparentemente banales es donde se detectan los cambios de alianzas, la mutación del favor real, la transformación de posibilidades para medrar dentro del propio grupo. Cita Elias un texto de La Bruyère muy ilustrativo:

Que un favorito se examine a sí mismo muy de cerca, pues, si se hace esperar en su antecámara menos de lo ordinario, si su rostro es más expresivo, si frunce menos el entrecejo, si me escucha con mayor agrado y si me acompaña un poco más allá, pensaré que empieza a caer y acertaré. (La Bruyère, Caracteres de la Cour, citado en Elias, 1993b: 141).

Pueden proponerse dos consecuencias de toda esta figuración, que obliga a la constante atención sobre la conducta propia y ajena en busca de oportunidades de prestigio. En primer lugar, el refinamiento progresivo de la conducta como manifestación externa de las diferencias de estatus entre grupos o facciones dentro de grupos. Para distanciarse simbólicamente, tenían ciertos privilegios de protocolo o adoptaban costumbres novedosas - y retrospectivamente más refinadas - . La segunda consecuencia relevante es la autocoacción afectiva y el autocontrol de los impulsos a los que se someten progresivamente todos los miembros de la sociedad cortesana. Su conducta queda, en términos globales, ampliamente medida y protocolizada. En palabras del académico de Leicester:

La competencia de la vida cortesana obliga así a un control de los afectos a favor de una conducta exactamente calculada y matizada en el trato con los hombres. La estructura configuracional, la estructura del trato social de los miembros de esta sociedad dejaba sólo un relativamente reducido campo a las espontáneas expresiones afectivas entre los mismos. (Elias, 1993b: 151).

Finalmente, antes de proseguir con la argumentación y discutir la pertinencia de las tesis eliasianas, conviene mencionar su idea de la «circulación de modelos», que tendremos que retomar más adelante en la discusión con las críticas que ha recibido. Con este concepto, se hace referencia al modo en que 
el refinamiento de la conducta y esa transformación de las estructuras afectivas hacia un mayor autocontrol se difunden por el conjunto de la sociedad. En este punto, el autor plantea, en términos generales, un modelo heurístico cercano a lo que se ha venido a llamar trickle-down-effect (Fallers, 1954; Baudrillard, 1970; Simmel, 1977), es decir, la difusión de conductas, prácticas y hábitos más estables entre grupos sociales debido al interés por emular al grupo privilegiado para acercarse a él —a efectos simbólicos y posteriormente materiales. Así, Elias propone que las conductas refinadas de las élites van extendiéndose a los grupos sociales de inferior posición social en la medida en que tratan de imitar y acortar las diferencias con ellas, asimilando también esos comportamientos distintivos:

La coacción que ejerce el entramado creciente de funciones para imponer una previsión mayor, una autodisciplina más estricta y una constitución más sólida del super-yo [la autocoacción] se hace visible, primeramente, en pequeños centros funcionales. Después va integrándose una cantidad superior de círculos funcionales dentro de Occidente. Finalmente, comienza en los países no europeos la misma transformación de las funciones sociales y, con ello, del comportamiento y del conjunto del aparato psíquico aunque todavía anclados en formas civilizatorias anteriores. (Elias, 1993a: 472)

\section{Revisión y ampliación de la tesis eliasiana}

Una vez esbozada la propuesta de Elias sobre el impulso civilizador promovido en los salones cortesanos, con la centralidad de la jerarquía y la emulación social que acogen en ellos, es el momento de presentar las objeciones más relevantes que ha recibido. Desde el punto de vista historiográfico, su modelo del proceso civilizador aplicado a la historia de Occidente ha recibido diversas críticas (por ejemplo, Barraclough, 1983; Kocka, 1994; Duindam, 1995, 1997). Para el tema que nos ocupa, uno de los más acérrimos opositores a sus tesis ha sido Daniel Gordon. Su objeción más general, compartida también por otros historiadores como Emmanuel Le Roy Ladurie (Le Roy Ladurie, 1997a, 1997b, 2003), es que Elias «exagera en gran medida el poder de la Corte como modelo de refinamiento de la conducta» (Gordon, 2003: 261). Además, añade que también están sobreestimadas en su modelo de los procesos de civilización las funciones de jerarquía y distinción en los entramados cortesanos. Esta crítica tan nuclear puede mantenerse, como veremos a continuación en el desarrollo de sus argumentos, contando con una serie de evidencias históricas y documentos diversos que ponen en entredicho las tesis de Elias. En palabras de Gordon:

La tendencia a igualar jerarquía y distinción es evidente en el trabajo de Elias y sus seguidores, y la aparente equivalencia de estas dos cuestiones es quizá el mayor obstáculo para la formulación de nuevas perspectivas de la significación sociológica de la actual preocupación por las buenas maneras. Aunque pudiera ser cierto que el cultivo de las maneras siempre sirviera a la necesidad 
grupal de gozar de un sentimiento de superioridad, no es necesariamente cierto que las formas cultivadas de distinción sean jerárquicas en su contenido. (Gordon, 2003: 265)

La crítica de Gordon no es compartida por otros historiadores, ni tampoco entre otros sociólogos que han seguido la estela de Elias en este punto, incluyendo al francés Pierre Bourdieu (cfr. Bourdieu, 1991: 72 y s.). Entre los historiadores que han defendido la validez de la visión de Elias, destaca Roger Chartier. Según este historiador francés, las reglas de conducta cortesanas y las maneras refinadas allí desarrolladas «aseguran una adecuada e interesante traslación de la jerarquía social» (Chartier, 1987: 45). Éstas y otras afirmaciones parecidas son aparentemente contradictorias con toda una serie de argumentos y testimonios históricos que Gordon y otros detractores ponen de manifiesto. En particular, puede rastrearse una amplia literatura de autores de aquellos tiempos modernos —ellos mismos asiduos a este tipo de reuniones sociales- que considera la existencia de salones sociales franceses, y europeos en general, como unas reuniones ciertamente elitistas en las que, no obstante, los rangos y las jerarquías quedan temporalmente en suspenso (cfr., por ejemplo, Goldsmith, 1988). De esta manera, la tesis eliasiana que propone la circulación de los modelos por capas sociales cada vez más amplias, a partir de las jerárquicas y distintivas reglas de conducta cortesanas, sería errónea en sus presupuestos fundamentales. Como sugiere Gordon, el error básico de Elias y sus partidarios consistiría en trasladar un ámbito social genérico donde la jerarquía vertebra las relaciones humanas a cualquier espacio de interacción social. En realidad, aunque la jerarquía y el rango regulen en términos generales ese histórico entramado social, no rigen en los salones sociales. Son, como diría Goffman, reglas irrelevantes en ese ámbito de interacción humana, pues es «diferente de todos los demás mundos excepto del que se genera cuando el mismo juego es jugado en otros momentos» (Goffman, 1961: 26-27).

Para mostrar esta irrelevancia del rango y la jerarquía en muchos salones sociales, Gordon trae a colación las numerosas obras sobre la conducta correcta y educada del prolífico Jean-Baptiste Morvan de Bellegarde, en su opinión poco conocido por la «monolítica interpretación de la cortesía como una forma de jerarquía" (Gordon, 2003: 267). Siguiendo la centralidad de su argumentación y sus referencias concretas, puede comprobarse que, en la obra de Bellegarde, el comportamiento cortés y los buenos modales, aunque son expresión de una distinción personal, ésta no está directamente vinculada a una jerarquía preexistente: «la valía de un hombre se decide según el modo en que se conduce en la conversación [...] Se le juzga de acuerdo con la impresión que ofrece de su persona en le commerce du monde» (Bellegarde, 1709: "Avertissement»). Esto significa que, aunque muchos de los miembros de la alta nobleza creyeran que su nacimiento era suficiente para conferirles prestigio, en realidad muchos de ellos carecían de las buenas maneras y del «delicado estilo» que eran signos de esa cortesía. Por ello, Bellegarde asegura que aquellos que no eran nobles en tan alta condición podían compensar su bajo 
nacimiento a través del cultivo de tales buenas maneras y un «aire gentil» (un air honnêtte y les belles manières), en tanto que éstas suponían en muchos casos un honor superior al favorecido por el nacimiento en el seno de una gran casa noble (cfr. Bellegarde, 1690).

Todos estos testimonios y argumentos parecen poner en entredicho las tesis centrales de Elias y de historiadores como Chartier acerca de la función esencial de las maneras cortesanas, a saber, la de reproducir las jerarquías sociales ya dadas. Sin embargo, en un análisis más detallado, lo reflejado hasta el momento en los argumentos de Bellegarde, bien podría ser suscrito por Elias.

En efecto, también se desprende de su análisis sociológico de la sociedad cortesana que el prestigio social no estaba garantizado por el nacimiento o la herencia familiar. De ser así, no habría habido necesidad de buscar el favor real que corre en paralelo al proceso de acortesamiento. Como hemos visto, Elias deja bien claro que el honor de la nobleza refleja un tipo de status consumption en el que tal prestigio ha de ser acreditado en el modo de vida y en el comportamiento (cfr. Elias, 1993b: 92 y s.). El resultado de ese consumo de prestigio y la importancia de la pertenencia a la «buena sociedad» diferenciada del resto lleva, en un proceso de varias generaciones intrincado con aspectos estructurales y un cambio en las estructuras de la personalidad, a una cuidadosa atención a las maneras. Esa exquisita mirada crítica y el progresivo amaneramiento es el cauce, en primer lugar, para la obtención del favor real. Tal condición de congraciamiento con el rey es, a su vez, la que permite mantener el prestigio y el honor, por lo que éste no es algo dado e irrevocable, como parece suponer Gordon en la interpretación que hace de Elias. Además, esa cuidadosa atención a las maneras, atavíos externos y rituales también tiene otra importante función: reflejar el propio honor. Un cortesano que no se comporte de acuerdo a las normas de etiqueta pierde honor, si así se quiere decir, no sólo porque pierda oportunidades de hacerse con el favor real, sino porque esas mismas formas son reflejo de ese estatus, de su misma calidad humana y social. Por lo demás, también hace notar Elias que, si la herencia familiar o la Casa a la que se pertenece es lo suficientemente poderosa, el margen para resistirse a esas normas de etiqueta puede ser relativamente mayor que en otros casos de más baja cuna. Por esto mismo, es posible señalar diversos intentos de resistirse a tal acortesamiento o de someterse a las intensas coacciones de la etiqueta (cfr. Elias, 1993b: 118-122, 285 y s.). Por tanto, el análisis eliasiano no es tan «monolítico» como pretenden Gordon y otros historiadores, y quizá por ello haya otras revisiones historiográficas que conceden a sus análisis una valía incuestionable, incluso a pesar de sus errores más significativos (cfr., por ejemplo, Chartier, 1992; Duindam, 1997; Aguirre Rojas, 1998).

Con todo, la revisión crítica que se hace de la propuesta eliasiana es valiosa y debe ser tenida en cuenta para ampliar y completar su fecundidad heurística de los procesos de civilización. La nueva perspectiva que se desprende del eje central de las objeciones es muy sugerente, y está presente no sólo en documentos históricos y literarios, sino también en análisis sociológicos como el que introduce Georg Simmel. Este sociólogo berlinés trata de manera ejem- 
plar la idea - ya contenida con anterioridad en muchos otros registros y utilizada para sus críticas por los detractores de las tesis de Elias- de la sociabilidad como actividad intrínsecamente agradable sin mayor finalidad que la de la propia satisfacción que produce. A efectos de lo que interesa en esta argumentación, el concepto de sociabilidad pura que propone Simmel se corresponde con los argumentos de Goffman en torno a las «reglas de irrelevancia» y la idea de Bellegarde del arte de la conversación como un modo de causar agrado a los participantes en ella (Bellegarde, 1696: 23; Goffman, 1961: 20 y s.; Le Roy Ladurie, 2003: 268-269). En el fondo de esta nueva perspectiva, yace la diferenciación entre los salones de la cortesía nobiliaria y los salones burgueses que, aunque ya coexistieron con los anteriores, proliferaron conforme ascendían en la escala social lo que actualmente podríamos denominar las clases medias.

La tesis de Gordon a este respecto — si he sabido leerle con acierto- consiste en sugerir que el impulso civilizatorio en la dirección de un refinamiento de las maneras no provino de manera fundamental de los ámbitos corteses que luego se difundieron a otras esferas sociales. Más bien, coexistieron con otro impulso, más burgués podríamos decir, que no puede ser una mera copia de las formas cortesanas, porque, en sus fundamentos éticos y teleológicos, difieren notablemente de ellas. En este sentido, los argumentos y las intuiciones sociológicas de Simmel sobre la «sociabilidad» describen bien lo que sostienen los representantes de esta literatura sobre la cortesía de los salones burgueses. Asimismo, servirán para aclarar estas diferencias y detallar la perspectiva adecuada que debe adoptarse sobre la revisión crítica que se ha hecho en este punto de las tesis de Norbert Elias.

\section{La sociabilidad pura en los salones sociales}

Los análisis de Simmel sobre los salones sociales provienen de su propia experiencia en Berlín. Frisby ha consignado, en su estudio sobre Simmel, el testimonio de Margaret Susman, que, como asistente a las veladas en el mismo salón de la casa de Simmel a finales del siglo XIX, pone de manifiesto la experiencia en este tipo de reuniones elitistas:

Los días de recibimiento en la casa de Simmel, los jours semanales, estaban enteramente concebidos en el espíritu de la cultura que sus concurrentes compartían. Era una creación sociológica en miniatura: la de una sociabilidad cuyo significado era el intercambio cultural de alta inteligencia. Cualquier conversación adquiría una forma [...] que flotaba en una atmósfera de intelectualidad, afabilidad y tacto, desligada de la carga última del elemento personal. Es indudable que Simmel logró la magistral disertación [...] sobre la sociabilidad gracias a su experiencia de esta sociedad selecta. Solamente gente excepcional, distinguida por su talento e incluso por su belleza, tomaba parte en estos acontecimientos sociales. (Susman, citado en Frisby, 1993: 56-57)

Partiendo de esta experiencia biográfica, la tesis central de Simmel, contenida en el apartado correspondiente de su obra Cuestiones fundamentales de 
sociología, consiste en que la sociabilidad, como forma pura, disuelve cualquier contenido teleológico en una forma lúdica de socialización:

Sólo lo sociable es 'una sociedad' sin más añadidos, porque, al elevarse por principio sobre cualquier contenido específico de todas las 'sociedades' de carácter unilateral, representa la forma pura en una imagen en cierto modo abstracta que disuelve todos los contenidos en el mero juego de la forma. (Simmel, 2002: 83)

Esta perspectiva de los salones sociales, desvinculados de cualquier finalidad fuera del mismo hecho de estar junto a otras personas, se corresponde, como hemos señalado, con la idea de las «reglas de la irrelevancia» de Goffman. También es coherente con los apuntes de Bellegarde, así como de otros autores como Méré o Callières, en los que se alude, asimismo, a esa única finalidad eudemonística de agradar a aquellos con los que uno entra en relación (Callières, 1696; Méré, 1930). Por tanto, no existen intereses materiales fuera del mismo hecho de la interacción social, o, en palabras de Simmel, más allá del «estar juntos puramente sociable» (Simmel, 2002: 83).

El atento sociólogo berlinés es consciente de que su análisis e interpretación de la sociabilidad como forma lúdica de la socialización es un «tipo ideal». En este sentido, sólo puede ser considerado como una construcción artificial: «la sociabilidad, si se quiere, crea un mundo sociológico ideal [...] es un mundo artificial, construido de seres que desean crear exclusivamente esta pura interacción entre ellos que no esté desequilibrada por ningún acento material» (Simmel, 2002: 88). Ahora bien, si esa gratificación o placer, ajeno a cualquier otra finalidad o interés concreto, se erige como el bien principal buscado por los participantes de la interacción, se plantea entonces la cuestión del origen de ese acuerdo tácito sobre la prevalencia de esta forma lúdica de la socialización. Propuesta de modo más sencilla, la pregunta a responder sería: ¿por qué ese interés exclusivo en la gratificación obtenida por el puro «estar juntos»? La respuesta a esta cuestión es análoga a aquélla que preguntara por el gusto y la búsqueda del juego por parte del hombre o incluso de otros animales. La solución de Simmel hace referencia a un «impulso de sociabilidad» que subyace a esta búsqueda humana del «estar junto a otros» sin finalidades o intereses ulteriores:

El impulso de sociabilidad en su actividad pura desprende de las realidades de la vida social el puro proceso de socialización como un valor y una forma de felicidad, y a partir de ellos constituye lo que llamamos sociabilidad en sentido más estricto. (Simmel, 2002: 82-83)

Tal impulso sociable (Gesselligkeitsfriebe) puede formularse de la siguiente manera: «cada cual ha de conceder al otro aquel máximo de valores sociables (de alegría, descarga, vivacidad) que es compatible con el máximo de los valores recibidos por uno mismo» (Simmel, 2002: 87-88). Por otra parte, dado el 
carácter antiutilitario de la forma pura de interacción que Simmel denomina sociabilidad, las reglas que puedan regir ese tipo de interacción social han de poseer también un carácter exclusivamente formal. De aquí la importancia concedida por el sociólogo berlinés al "sentido del tacto", esto es, al refinamiento de las maneras y a la conducta en relación con otros, que servirá como guía para la autorregulación normativa del individuo en tanto que logre «poner límites a las impulsividades individuales, a la acentuación del yo y a las exigencias espirituales e internas que exige el derecho del otro" (Simmel, 2002: 84-85).

Como puede apreciarse, la naturaleza de este tipo de interacción social exige una puesta-en-reserva de los rasgos más singulares de los participantes en ella. El resultado es «un juego en el que se hace como si todos fueran iguales y al mismo tiempo como si se hiciera honor a cada uno en particular", y esto no es mentira «en la misma medida en que tampoco son mentira el juego o el arte con todas sus desviaciones de la realidad» (Simmel, 2002: 90).

Este análisis simmeliano de los requisitos de la sociabilidad como forma pura de socialización se corresponde bien con los planteamientos de los autores citados por Gordon, como cuando Méré afirma que uno «debe ponerse a sí mismo en el lugar de aquellos a quienes quiere agradar», acomodándose a los demás en todas las formas y conductas que contribuyan a esa interacción, de manera que se cumplan los requisitos de conformidad y simpatía (conformité y sympathie), incluso si ello supone acomodar el discurso hablado al oyente particular con el que estamos en relación (Méré, 1930: 106). La idea del artificio de la igualdad puede apreciarse también en diversos textos de Callières, como cuando recoge la máxima de que «conviene nos acostumbremos a hablar a nuestros iguales como si fuesen superiores y a los inferiores como si fuesen iguales» (Callières, 1778: 78-79). Éstas y otras afirmaciones análogas expresan nítidamente la existencia de dos órdenes, aquél en el que existen las jerarquías y el propio de la sociabilidad en el que se finge su inexistencia (Gordon, 2003: 276). Ambos textos, el de Méré y el de Calliéres, guardan una esclarecedora semejanza con este otro de Simmel, que apunta también a esas ideas de acomodamiento y fingimiento de igualdad: «el sobresaliente no sólo se pone al mismo nivel con los más débiles, sino incluso adopta una actitud como si el otro fuese el más valioso y superior» (Simmel, 2002: 89).

En este microcosmos de interacción humana ajeno a rangos y jerarquías, el arte de hablar y de la conversación ocupan una posición ejemplar que reúne toda la caracterización de esta forma lúdica de socialización. Como afirma Craveri:

Nacida como un puro entretenimiento, como un juego destinado a la distracción y al placer recíproco, la conversación obedecía a leyes severas que garantizaban la armonía en un plano de perfecta igualdad. Eran leyes de claridad, de mesura, de elegancia, de respeto por el amor propio ajeno. El talento para escuchar era más apreciado que el talento para hablar, y una exquisita cortesía frenaba la vehemencia e impedía el enfrentamiento verbal. (Craveri, 2003: 18) 
No resulta extraño, por ello, que tanto Simmel como todos los autores que comparten su análisis sobre este tipo de encuentro social aludan en particular a estas formas sociables de comunicación. Así, por ejemplo, Simmel afirma que «en la conversación puramente social, la materia ya no es más que el soporte imprescindible de los atractivos que despliega por sí mismo el vivo intercambio de la conversación» (Simmel, 2002: 94). Por su parte, Medeleine de Scudéry diferencia entre aquéllos que hablan de «sus intereses y sus asuntos» de los que mantienen una verdadera conversación social, que es aquella que se mantiene por sí misma, por el mero hecho de conversar, sin finalidad ulterior, y que constituye «el más dulce placer de la vida» (Scudéry, 1907: 240). También pueden encontrarse estas mismas ideas, en un contexto bien diferente, en los análisis sobre estas cuestiones elaborados por Gabriel Tarde, quien asegura que «la conversación tiende a hacer iguales a los interlocutores, al comunicar a unos con otros, y socava las jerarquías a fuerza de facilitarles la expresión» (Tarde, 1986: 120).

A la luz de todo lo anterior, podemos alcanzar la conclusión preliminar de que la sociabilidad de la que habla Simmel es un ámbito de las relaciones sociales en las que el conflicto debe ser sometido a las exigencias del arte de agradar al otro y de disfrutar de la relación misma. No obstante, la exigencia de autorregulación que permite la realización de este tipo de interacción social supone una estilización de las conductas que impide, precisamente, ese potencial conflicto o desencuentro entre los derechos de unos y de otros. En otro contexto, Simmel había acotado su concepto de estilo, que da razón de este argumento:

El estilo, en cuanto a la expresión de nuestros procesos internos, significa que éstos ya no manan de repente hacia el exterior, sino que, en el momento de su manifestación, cambian de apariencia. Como configuración general de lo individual, el estilo es la envoltura de esto que, al mismo tiempo, supone una limitación y un distanciamiento, frente a la otra persona, que es la que recibe la expresión. (Simmel, 1977: 597).

De acuerdo con esto, en estas reuniones sociales simuladamente igualitarias, donde se crea un artificio de relaciones autorreferenciales, sólo cabe una normatividad formal. Esas prescripciones puramente formales de la conducta están ordenadas a la finalidad de evitar cualquier circunstancia que pusiera en peligro el agrado y disfrute que constituye la misma relación sociable. Ello implica, en consecuencia, un ámbito manifestativo en el que la forma de la conducta queda estilizada y lo más personal y diferenciador debe ser suprimido. En suma, la estilización propia de este tipo de reuniones sociales supone de hecho una afectación o un amaneramiento en el modo de hablar y conversar, de reírse, de escucharse, de mirar y entristecerse, de elogiar o criticar. Y es precisamente esta afectación la que provoca que la conducta puramente sociable pueda apreciarse como algo falso (cfr. Múgica, 2003: 53). Sintetizado por el mismo Simmel:

La riqueza y la posición social, la erudición y la forma, capacidades excepcionales y méritos del individuo, no han de jugar ningún papel en la sociabili- 
dad, o como mucho pueden dar un leve acento de aquel carácter inmaterial con el que únicamente se puede introducir la realidad en el artificio social de la sociabilidad. Lo mismo que estos elementos objetivos que rodean a una persona, también debe quedar suprimido lo más puro y profundamente personal en su función como componente de la sociabilidad: lo más específicamente personal de la vida, del carácter, del estado de ánimo, del destino, tampoco tienen un lugar en la sociabilidad. (Simmel, 2002: 85)

Dada esta estilización de la conducta en el plano manifestativo de la sociabilidad, las conductas dentro de tal contexto interactivo pueden ser comprendidas estéticamente, esto es, como un arte. Por ello es posible encontrar constantemente referencias al «arte de hablar», al "arte de conversar» o al "arte de agradar» como componentes de esta sociabilidad. En cualquier caso, este carácter estético lleva consigo asociado, tanto en Simmel como en la mayoría de los autores que venimos comentando, un carácter ético que permanece latente. Así, abundantes escritos sobre educación y cortesía presentan las reglas de la conversación como reglas morales -e incluso religiosas-, que se fundamentan en esa búsqueda del agrado ajeno, de la benevolencia (Gordon, 2003: 283-291).

Antes de retomar la línea argumental de este escrito y alcanzar algunas conclusiones, conviene dejar consignado que la posición de Simmel en relación con este carácter ético del entramado, aunque coincida en el diagnóstico con muchos otros documentos de autores diversos, es más compleja. En efecto, su afirmación de que «la sociabilidad es también la forma lúdica de las fuerzas éticas de la sociedad" (Simmel, 2002: 96) ha de ponerse en relación con toda su teoría de la vida expresada en la forma y la ambivalencia que ello encierra: la reserva con la que el hombre entra en el contexto lúdico - artístico- de la sociabilidad y sus manifestaciones, le permite a la vez esa dualidad expresada en sus apriorismos sociológicos de la condición simultánea del hombre como «ser para sí mismo" y "ser para la sociedad", una ambivalencia entre compromiso y distancia que caracteriza su misma naturaleza social. En este sentido, la forma lúdica que constituye la sociabilidad a modo de reconstrucción artística es un símbolo de la vida que, a través de la forma que la limita, se expresa. En definitiva, como resume Simmel, la sociabilidad:

[...] excluye la realidad de las interacciones realistas entre las personas y construye su reino en el aire según las leyes formales de estas relaciones que se mueven a sí mismas y sin aceptar fines que estén fuera de ellas. Sin embargo, la fuente subterránea que alimenta las movilidades de este reino, no se ha de buscar en estas formas que se determinan a sí mismas, sino sólo en la vivacidad de los individuos reales, en sus sentimientos y atracciones, en la abundancia de sus impulsos y convicciones. (Simmel, 2002: 99, cursiva mía).

\section{Conclusiones}

Una vez esbozados los argumentos más fundamentales sobre los salones burgueses en los autores que describen la —utilizando el concepto simmeliano- 
sociabilidad que en ellos se representaba, cabe alcanzar algunas conclusiones en relación con la crítica historiográfica central a la perspectiva eliasiana.

En primer lugar, puede afirmarse que estas objeciones resultan en ocasiones excesivas y olvidan diversas ideas de su análisis sobre la sociedad cortesana y de su teoría de los procesos civilizadores. No obstante, la existencia documentada de otras fórmulas y lógicas de interacción humanas, alternativas y de naturaleza distinta a las basadas en las jerarquías y los rangos que regían los salones aristocráticos, ponen de manifiesto la posibilidad y la necesidad de ampliar la perspectiva de Norbert Elias. Con ello, se abre un campo relativamente amplio y fértil para el refinamiento de algunas de sus consideraciones más generales. En términos globales, coincido en el diagnóstico de que la propuesta presentada por Elias es parcial y sólo en esa medida alcanza a explicar la riqueza y los matices albergados en la historia de las costumbres, la cortesía o las buenas maneras. Se podrían indicar algunas de las líneas de desarrollo, que, por razones de espacio, no pueden ser tratadas en este trabajo, tales como: la vertiente moral que vertebra muchas de las iniciales y más ejemplares contribuciones a la cortesía (Courtin, 1708; Erasmo de Rotterdam, 1985; Chartier, 1993), la importancia de conceptualizar todas estas reglas de conducta como instrumento adecuado y facilitador de la participación social (Gracián, 1968; Della Casa, 1994; Laspalas, 2003); o la crucial influencia de las órdenes religiosas en la transmisión de estas pautas de comportamiento, que diversos comentadores han puesto de manifiesto recientemente (Goudsblom, 2004; Turner, 2004). En cualquier caso, la parcialidad de una argumentación como la de Elias, encaminada a mostrar un ejemplo de «impulso civilizador» dentro de su teoría más global de los procesos de civilización, no debe rechazarse por los elementos que no contempla en sus análisis, sino motivar una ampliación de su perspectiva contando con lo que ésta tiene de válido.

Más centrados en los argumentos aquí discutidos, todos los apuntes críticos que han sido mostrados aciertan en su idea de que Elias y sus seguidores exageran la importancia de la Corte y el impulso formalizador o de refinamiento de las maneras que en ella comparece como el eje explicativo central de ese proceso de la civilización de las costumbres. Las evidencias recogidas de numerosos autores, y condensadas en el análisis simmeliano de la sociabilidad en los salones burgueses, muestran que convivieron y proliferaron otras reuniones sociales en las que también se ejerció un impulso formalizador y que no pueden considerarse una mera copia o traslación al mundo burgués de los modelos cortesanos. No puede serlo habida cuenta de las diferencias de justificación y comprensión de tales reuniones sociales. Del mismo modo, la idea reflejada por Elias de que los refinamientos cortesanos tenían la función de reproducir las jerarquías sociales no se corresponde con el ideal igualitario que regía en estos otros salones de sociedad. Tampoco cabría explicar desde la perspectiva eliasiana la ausencia de finalidad más allá del deseo de agradar y disfrutar con la misma relación sociable. Más concretamente aún, el uso del argot y las nuevas acuñaciones lingüísticas que Elias evidencia a partir de testimonios de cortesanos con la finalidad de distinguirse de la burguesía está en contradicción con 
la ridiculización de estas modas que ya en aquel tiempo realizaron algunos autores (Callières, 1696). En consecuencia, el criterio de jerarquización social y la función de distinción que vertebra la explicación eliasiana del impulso formalizador procedente de los estratos cortesanos es insuficiente, o parcial.

En mi opinión, sin embargo, coincidiendo en que el cuadro dibujado por Elias no abarca la totalidad de prácticas sociales esenciales para comprender los procesos particulares de civilización, los críticos que descartan de manera más o menos absoluta la aportación de sus tesis a la comprensión de estos procesos no aciertan a ver la mayor amplitud de sus planteamientos. Considero que sus detractores más acérrimos incurren en tres errores de apreciación de su obra, y tales incomprensiones explican su conclusión acerca del escaso valor heurístico que aporta.

Un primer error consiste en olvidar el contexto general más abarcante y algunas suposiciones metodológicas centrales de la sociología de Elias. En este sentido, el impulso civilizador que se aprecia en la sociedad cortesana no responde únicamente a esa función de distinción social, aunque la contemple. Las condiciones estructurales y los equilibrios de poder, en conjunción con las transformaciones profundas de la estructura de la personalidad en un proceso de varias generaciones, no pueden ser olvidadas en una consideración prácticamente estática de la sociedad cortesana. No cabe hacer una interpretación de Elias en perspectiva sincrónica. Las críticas más serias que ha recibido en este sentido parecen olvidar el carácter procesual de sus análisis y temas, y tienden a considerar sus afirmaciones concretas desvinculadas del largo recorrido histórico en el que este sociólogo las inserta. Bien al contrario, la sociología de Elias es una sociología de procesos, de grandes transformaciones sociales (Krieken, 1998; Mennell, 1998). En su propuesta, es fundamental la sociogénesis de la Corte, así como la psicogénesis que lleva asociada en el advenimiento de ese impulso civilizador que es especialmente acusado y representativo en la sociedad cortesana por la figuración específica en la que se ha desembocado tras un largo proceso histórico. Las objeciones a su tesis no pueden, en consecuencia, pasar por alto las consideraciones dinámicas y de transformación histórica a las que apunta continuamente, haciendo omisión de la procesualidad más compleja que encierra.

El segundo error de apreciación reside en no contemplar las motivaciones axiológicas que Elias se esfuerza por subrayar como facilitadoras de la figuración cortesana, así como sus implicaciones para la conducta personal en el plano manifestativo. En sus análisis, ha puesto de relieve que la búsqueda de prestigio que caracteriza al específico ethos cortesano - basado en el status consumption - implica necesariamente que tal prestigio no venía dado de antemano, sino que era preciso mantenerlo precisamente a partir de ese consumo, es decir, de conductas reconocidas como apropiadas a tal estatus. Y el hecho de que tuvieran que ser reconocidas implica un paso decidido al plano manifestativo. Esta necesaria implantación y presencia en el ámbito de lo público impulsa también la atención a las conductas que se hacen progresivamente más importantes en la búsqueda de oportunidades de poder, especialmente en 
cuanto búsqueda del favor real. A resultas de todo ello, la figuración exige el empleo creciente de medios pacíficos y más calculados, lo cual propicia los procesos de «psicologización» y «racionalización» a los que alude Elias.

Finalmente, el tercer error radica en no advertir los breves apuntes que este sociólogo deja consignados en torno a contextos de interacción alternativos a los que él estudia, pero que pueden ser incluidos en su propia lógica argumental. En realidad, la existencia de los salones donde priman formas igualitarias y estilizadas propias de la sociabilidad, contrapuestos a las reuniones sociales predominantemente aristocráticas donde primaría la jerarquía, no está en pugna, según me parece, con la tesis eliasiana. En todo caso la amplía, en el sentido de proporcionar una explicación añadida a las luchas entre burguesía y nobleza. Pero esta tensión está ya tematizada y presente en la obra del sociólogo de Breslau.

Recordemos el argumento central: los salones sociales no jerárquicos, tal y como son presentados por los argumentos de Gordon y demás críticos, parecen orientados a contraponerse específicamente a los criterios más significativos de la aristocracia a la que, como grupo social, se oponen. Así, frente a la jerarquía, el igualitarismo; en oposición a la función de distinción de las maneras y las formas refinadas, el deseo de agrado o «impulso sociable» como finalidad intrínseca; frente a la amoralidad que caracteriza la formalidad aristocrática, la moral subyacente al carácter estético de la relación sociable... Así presentada, esta caracterización de ambos tipos de reuniones sociales parece reflejar bien la oposición, tematizada y comentada por Elias, entre estos grupos sociales y los valores e imágenes que han servido como instrumento de lucha a las clases burguesas en su ascenso social a costa de la nobleza. Así, por ejemplo, en oposición a esta moralidad e igualitarismo como valores propios de los salones sociales burgueses, las normas de etiqueta propias de la sociedad absolutista y aristocrática son presentadas como una mera sumisión jerárquica carente de toda significación moral (Elias, 1993a: 61y ss.). La conducta adecuada para el noble cortesano no es otra que la obediencia a los gustos del señor, el rey como cúspide de la jerarquía social, que puede favorecer sus intereses y su búsqueda de oportunidades de poder. Debe atenerse a sus caprichos más nimios, incluso cuando éstos contradigan lo que puede considerarse como dignidad o sentido moral (Refuge, 1616; Faret, 1925).

Más aún, el propio Elias, en sus análisis acerca de la difusión de los comportamientos propios del proceso civilizador, propone dos fases diferenciadas, pero que pueden convivir en el tiempo. La primera es la fase de asimilación, en la que las pautas y las conductas "civilizadas» adoptadas en un círculo reducido y diferenciado se difunden a grupos en ascenso que tienden a imitar o emular esas prácticas para igualarse en oportunidades. El grupo selecto y prevalente, por tanto, logra imponer con cierta facilidad sus formas de comportamiento, en parte como medio de distinción y mantenimiento de su estatus social frente a las pretensiones de los nuevos grupos en ascenso. Se da, en esta fase de asimilación, una progresiva igualación de abajo hacia arriba, y se mantiene la influencia y cierta capacidad de dominio desde arriba hacia abajo. Sin embar- 
go, este modelo puede convivir con una alternativa y habitualmente deviene en ella: es la fase de rechazo. En este escenario, al haberse acrecentado la fortaleza social y de estatus de los grupos en ascenso, y después de una progresiva igualación y debilitamiento de los contrastes, se consolida una conciencia de clase entre los grupos en ascenso que tiende a destacar y a consolidar su carácter diferencial con respecto a los modelos y pautas de las anteriores clases superiores, ahora debilitadas en su estatus y su capacidad de influencia (Elias, 1993a: 514-517). Esto significa, también, que las formas de comportamiento no se transfieren únicamente de arriba hacia abajo, sino que, con el cambio del centro de gravedad social, se transfieren asimismo de abajo hacia arriba.

Así puede apreciarse, por ejemplo, en los movimientos de ascenso de la burguesía, donde el código de comportamiento aristocrático-cortesano perdió mucha rigidez y las formas de trato y de convivencia social se hicieron más flexibles, e incluso se vulgarizaron. En definitiva, como explica Norbert Elias:

La idea principal de este movimiento civilizador, el ascenso progresivo de capas cada vez más amplias, es el mismo en todos los países de Occidente, y análogo en ámbitos no occidentales, siendo también las mismas leyes estructurales que subyacen al movimiento, esto es, la creciente especialización funcional bajo la presión de la competencia, la tendencia a una interdependencia homogénea que iguala a largo plazo la fuerza de todos los grupos funcionales al tiempo que aniquila los privilegios hereditarios. Idéntico es, asimismo, el curso de las luchas de competencia libre: éstas conducen a la constitución de monopolios centrados en pocas manos y por último a la transferencia del poder de disposición sobre los monopolios a manos de capas más amplias de población. (Elias, 1993a: 518)

Desde este esquema de interpretación de los procesos de difusión, más complejo del que parecen tener en cuenta las objeciones mencionadas, pueden ser incluidos esos salones alternativos a los propios de la jerarquía aristocrática. La oposición entre grupos sociales en ascenso y los más genuinamente aristocráticos hacen posible la coexistencia de fórmulas de reunión social alternativas, en las que, precisamente, las normas y los presupuestos éticos o teleológicos de unos y otros son presentados como antagónicos, del mismo modo que están en pugna esos grupos en su lucha por mayores oportunidades de poder. Aunque sea cierto que Elias no desarrolla esta perspectiva ni analiza con detalle la función de los salones burgueses en el proceso de formalización de la conducta, es un error pasar por alto sus anotaciones al respecto.

Cabe concluir, por tanto, que existe un ámbito únicamente indicado y probablemente poco explorado por Elias en su análisis del impulso civilizador promovido durante la sociedad cortesana. Se trata de esos salones sociales alternativos, sin jerarquías ni rangos, que Simmel propone como paradigma de la forma de sociabilidad pura. No obstante, de esta escasa atención de Norbert Elias a estas otras formas de reunión social, en las que también se produjo un impulso en la dirección del refinamiento de las maneras y las conductas socia- 
les, no puede deducirse que su teoría de la civilización y sus observaciones sobre la figuración cortesana carezcan de valor. Ni sus análisis son tan «monolíticos» como pretenden algunos críticos, ni es tan acusado el énfasis en la reproducción de una jerarquía preexistente con el objetivo único de distinción social. Con todo, la inclusión de esta perspectiva de los salones más burgueses, cuyos principios dinámicos diferenciados de los salones aristocráticos de la nobleza pueden comprenderse como parte de la tensión y la lucha entre ambos estamentos, enriquece notablemente la argumentación eliasiana y abre una interesante vía para el refinamiento de sus propuestas con investigaciones que sigan esta dirección.

\section{Referencias bibliográficas}

Aguirre Rojas, Carlos Antonio (1998). «Norbert Elias: Historiador y crítico de la modernidad». ER. Revista de Filosofía, 23, 107-130.

BARRAClOUGH, Geoffrey (1983). «El proceso civilizador». Revista de Occidente, 20, 115-121.

Baudrillard, Jean (1970). La société de consommation. París: Denoel.

BelLEGARDE, Jean-Baptiste Morvan de (1690). Réflexions sur ce qui peut plaire ou déplaire dans le commerce du monde. Amsterdam: Abraham Wolfgang.

- (1696). Réflexions sur le ridicule et sur les moyens de l'éviter. París: Jean Guignard.

- (1709). Modeles de conversation pour les personnes polies. Amsterdam: Guignard.

Bourdieu, Pierre (1991). La distinción. Criterios y bases del gusto. Madrid: Taurus.

Callières, François de (1696). Des mots á la mode et des nouvelles façons de parler. París: Claude Barbin.

- (1778). Tratado de la ciencia del mundo, y de las noticias útiles para la conducta de la vida. Madrid: Blás Román.

CourTin, Antoine de (1708). Nouveau Traité de la civilité qui se pratique en France parmi les honnêtes gens. Amsterdam: Henri Schelte.

CRAVERI, Benedetta (2003). La cultura de la conversación. Madrid: Siruela.

CHARTIER, Roger (1987). Lectures et lecteurs dans la France d'Ancien Régime. París: Seuil.

- (1992). El mundo como representación. Barcelona: Gedisa.

- (1993). Libros, lecturas y lectores en la Edad Moderna. Madrid: Alianza.

Della CaSA, Giovanni (1994). Galateo. Turín: Einaudi.

DUINDAM, Jeroen (1995). Myths of power. Amsterdam: Amsterdam University Press.

- (1997). «Beyond Elias? Court Society: The centre as symbol and locus of power». Figurations, 8.

ELIAS, Norbert (1993a). El proceso de la civilización: Investigaciones sociogenéticas y psicogenéticas. México: Fondo de Cultura Económica.

- (1993b). La sociedad cortesana. México: Fondo de Cultura Económica.

ERASMO DE ROTTERDAM (1985). De la urbanidad en las maneras de los niños (De civilitate morum puerilium). Madrid: MEC.

FALlers, Lloyd A. (1954). «Fashion: a note on the "trickle effect"». Public Opinion Quarterly, 5 (18), 402-405.

FARET, Nicolas (1925). L'Honnête homme, ou l'art de plaire à la cour. París: Alcan. FrISBY, David (1993). Georg Simmel. México: Fondo de Cultura Económica.

GOFFMAN, Erving (1961). Encounters. Indianapolis: Bobbs-Merrill. 
Goldsmith, Elisabeth C. (1988). Exclusive Conversations: The Art of Interaction in Seventeenth Century France. Filadelfia: University of Pennsylvania Press.

Gordon, Daniel (2003). "The Civilizing Process Revisited». En: Dunning, Eric y Mennell, Stephen (eds.). Norbert Elias. Londres: SAGE Publications, 4, 259-300.

GoudSBLOM, Johan (2004). "Christian religion and the European civilizing process: The views of Norbert Elias and Max Weber compared in the context of the Augustinian and Lucretian traditions». En: LOYAL, Steven y QUILLEY, Stephen (eds.). The sociology of Norbert Elias. Nueva York: Cambridge University Press, 265-280.

Gracíán, Baltasar (1968). Oráculo manual y arte de prudencia. Anaya: Salamanca. KOCKA, Jürgen (1994). "Norbert Elias desde el punto de vista de un historiador». Revista Española de Investigaciones Sociológicas, 65, 93-101.

KRIEKEN, Robert van (1998). Norbert Elias. Londres: Routledge.

LASPALAS, Javier (2003). «La "cortesía” como forma de participación social». Anuario Filosófico, XXXVI (1), 311-343.

Le Roy Ladurie, Emmanuel (1997a). «La deuxième mort de Norbert Elias». Le Figaro, 30, enero.

- (1997b). Saint-Simon. París: Fayard.

- (2003). «Trop polis pour être honnêtes». En: Dunning, Eric y MEnNELL, Stephen (eds.). Norbert Elias. Londres: SAGE Publications, 4, 245-248.

Mennell, Stephen (1998). Norbert Elias. An introduction. Dublín: University College Dublin Press.

MÉRÉ, Antoine Gombaud (1930). «De la conversation». En: BoudHOURS, Charles H. (ed.). Oeuvres complètes. París: F. Roches.

MúGICA, Fernando (2003). «Individuo y sociedad. La aportación de las Cuestiones Fundamentales de Sociología». Cuadernos de Anuario Filosófico. Serie de Clásicos de la Sociología, 9, 5-111.

Refuge, Eustache de (1616). Traité de la cour. París: Jean Guignard.

SCUdÉRY, Madeleine de (1907). «De la Conversation». En: CrANE, Thomas F. (ed.). La Société française au dix-septième siècle. Nueva York: G.P. Putnam's Sons.

Simmel, Georg (1977). Filosofía del Dinero. Madrid: Instituto de Estudios Políticos. - (2002). Cuestiones fundamentales de sociología. Barcelona: Gedisa.

TARDE, Gabriel (1986). La opinión y la multitud. Madrid: Taurus.

TURNER, Bryan S. (2004). «Weber and Elias on religion and violence: warrior charisma and the civilizing process». En: LoYAL, Steven y Quilley, Stephen (eds.). The sociology of Norbert Elias. Nueva York: Cambridge University Press, 245-264.

VEBLEN, Thorstein (1991). The theory of the leisure class. Fairfield: Kelley.

Weber, Max (1922). Wirtschaft und Gesellschaft. Tubinga: J.C.B. Mohr. 